\title{
Method for choosing a scheme of placing navigation signs on a section of inland waterways for navigating a vessel with a given navigation risk value
}

\author{
Vladimir Karetnikov ${ }^{1, *}$, Denis Milyakov ${ }^{2}$, Andrey Prokhorenkov ${ }^{1}$, and Konstantin Efimov ${ }^{1}$ \\ ${ }^{1}$ Admiral Makarov State University of Maritime and Inland Shipping, Dvinskaya Street, 5/7, 198035, \\ St Petersburg, Russia \\ ${ }^{2}$ JSC "KB NAVIS", Saint Petersburg, Russia
}

\begin{abstract}
This paper is devoted to the method of choosing a scheme for placing navigation signs on sections of inland waterways to ensure the navigation of vessels with a given level of navigation risks. The methods used are known from the theory of probability and mathematical statistics for the assessment of navigation risks, which is proposed to be performed by stochastic methods, estimating the dis-placement of the center of the vessel's size and the variability of the maneuvering lane. It is shown that according to the results of mathematical modeling of the controlled movement of the vessel along the difficult for navigation section "Ivanovskie Porogi" on the Neva river, these navigation parameters are subject to the normal distribution law. This made it possible to reduce the problem of risk assessment to the problem of finding the probability of a random variable hitting the designated lane. A formal assessment of the navigational risk of navigating a vessel through a section that is difficult for navigation was carried out, on the ba-sis of which it is possible to judge the quality of the vessel's control and the prob-ability of the vessel going beyond the edge of the fairway. The results presented in this work were obtained during the implementation of the INFUTURE international project.
\end{abstract}

\section{Introduction}

The specific sailing conditions in inland waterways also determine the uniqueness of the navigator's work when navigating the ship. The navigator must not only ensure a high level of navigational safety of navigation, but also the most efficient operation of the vessel. With regard to inland waterways, this means that it is necessary to choose the course of the vessel so that the speed of movement is the highest, the distance is the smallest, and the hazards are at a sufficiently large distance. For this, the navigator needs to quickly assess the available water space, which is safe for the movement of the vessel, taking into account its draft and the actual water level. 3D maps provide the function of displaying the area of

\footnotetext{
* Corresponding author: karetnikovvv@gumrf.ru
} 
dangerous depths, dividing the water area covered by the map into areas of dangerous and safe depths.

In accordance with the regulatory documents [1-3], in the event of any circum-stances that complicate navigation and may create a danger to the vessel, the captain must take navigation directly upon himself and give instructions required by the situation. However, when navigating along inland waterways, especially along areas that are difficult for navigation, the navigational situation around the vessel may change in an unpredictable manner, which excludes the possibility of calling the captain in advance to take over his navigational responsibilities. Therefore, it becomes necessary to solve the problem of assessing the competence of the navigator and his ability to make decisions on how to navigate the ship in various sailing conditions. This paper provides an assessment of the risks of navigating vessels of mixed "river-sea" navigation along the section of inland waterways, which is difficult for navigation.

The navigation of a ship in inland waterways is influenced by numerous factors that relate to the ship, the navigator and the environment. The current stage of development of means and systems of navigation is characterized by an increasing contradiction between high requirements for the safety of navigation, on the one hand, and a fairly high level of navigational accidents in inland waterways, on the other hand. This largely determines both the need for further improvement of navigation aids and systems, as well as the development of mathematical and systemic methods for analyzing the factors and causes of the occurrence of navigation situations, a comprehensive and holistic description of a set of events leading to dangerous navigation situations, as well as the analysis of the consequences of the development of dangerous navigation situations.

\section{Methodology for formalized safety assessment}

The results of the search for ways to describe the effect of a combination of hazardous factors on the quality of navigation led to the creation of methods for a formalized assessment of navigational safety (FAS) [4-6].

Below are the results of generalization of the levels of navigation risks of various types of ships according to the IMO data [7], obtained using the FAS methodology (Table 1).

Table 1. Generalized characteristics of navigation risks (according to IMO data for different classes of ships).

\begin{tabular}{|c|c|c|c|c|c|}
\hline No. & Ship type & Collisions & Grounding & Lean & Maximum risk \\
\hline 1. & Passenger ships & $4.6 \times 10^{-3}$ & $9.8 \times 10^{-3}$ & $1.2 \times 10^{-3}$ & $1.6 \times 10^{-2}$ \\
\hline 2. & Ro-ro ships & $1.25 \times 10^{-2}$ & $4 \times 10^{-3}$ & $1.25 \times 10^{-2}$ & $2.9 \times 10^{-2}$ \\
\hline 3. & Container ships & $1.64 \times 10^{-2}$ & $6.84 \times 10^{-3}$ & $3.65 \times 10^{-3}$ & $2.7 \times 10^{-2}$ \\
\hline 4. & Gas carriers & $6.7 \times 10^{-3}$ & $2.8 \times 10^{-3}$ & $2.8 \times 10^{-3}$ & $1.2 \times 10^{-2}$ \\
\hline
\end{tabular}

It should be noted that the maximum value of the level of navigation risk for different types of ships is approximately the same and amounts to $(1.2 \div 2.9) \mathrm{x} \cdot 10-2$ per year. This characteristic shows that navigation risks are integral qualitative properties of the operation of maritime organizational and technical transport systems.

The process of controlling a vessel by the pilotage method, i.e. based on the visual determination of the position of the vessel and the direction of its movement, is difficult to describe by strict dependencies. Therefore, it is advisable to use a formalized assessment of safety (FAS) based on the method of controlled movement of the vessel with subsequent probabilistic assessment of the numerical values of navigation risks. 
FAS is a preventive safety assessment in high-risk areas of activity, the purpose of which is to assess and reduce possible risks, as well as the costs and benefits of decisions aimed at reducing these risks.

The main approaches to risk assessment and the development of solutions to counter emerging risks are set out in the manual [8], which defines the basic terminology for FAS and its methodology. The methodology includes five main stages:

1. Identification of hazards;

2. Risk analysis;

3. Determination of risk management methods;

4. Assessing the cost and savings in adopting certain risk management techniques;

5. Recommendations for decision making.

The FAS methodology developed by the International Maritime Organization is a structured and systematic methodology for improving safety through the use of risk assessments and risk management, taking into account the costs of various types of resources.

Under the navigational safety (Rns), we mean the probability of the vessel passing through the narrow areas without committing a navigation incident. Accordingly, the risk (R) will be equal to $\mathrm{R}=1$ - Pns.

When implementing the FAS methodology, the processes of full-scale and simulation modeling are often used. Their main advantage is the ability to predict changes in risk assessments over time with statistical (as a rule, random) variations in the initial data.

It should be noted that currently, there are no generally accepted methods for assessing and managing risks. There are several reasons for this:

1. The behavior of navigation systems is poorly formalized by the existing methods.

2. The need to introduce a navigator into the object of research requires the development of specific approaches to take into account his activities and the impact on the consequences for the navigation system.

3. The navigation system is a multidimensional and multifunctional organizational and technical system, which has a rather complex structure of components and connections between them.

4. The manifestation of various properties and factors affecting the navigation system is of a probabilistic nature and therefore can be taken into account only for the set.

It follows from the foregoing that the assessment of navigation risks is a difficult matter, theoretical methods and working methods do not exist, which determines the relevance and objective difficulty of such works.

Existing approaches are based on systems theory and operations research methods. At the same time, they try to describe the qualitative properties of the system under study and their influence on the achievement of a certain goal by the system under study.

Taking into account the probabilistic nature of the influence of factors on the system, the main goal is to determine the probability of achieving the goal of the system.

These approaches have several disadvantages.

1. Difficulties in adequately describing and formalizing the system.

2. The problem of initial data, when the properties of non-measurable factors are difficult or impossible to describe by formal methods.

The main criterion for assessing the state of ensuring the safety of navigation, according to the Federal Service for Supervision of Transport, should be the level of risk in the implementation of navigation. The main task of the safety system for navigation is to ensure an acceptable level of risk.

The main causes of traffic accidents in river transport are as follows:

1. choosing a wrong maneuver,

2. errors in orientation, 
3. lack of taking into account the action of external factors affecting controllability,

4. incorrect assessment of the data of electro-radio navigation devices,

5. other navigation errors;

6. failure to ensure safe practice of ship operation by shipowners;

7. insufficient maintenance of vessels in a good technical condition;

8. failure of the ship's crew, shipowner or shore workers to comply with the requirements established in regulatory documents on the safety of navigation;

9. violation of labor discipline by the ship's crew;

10. negligence of the ship's crew towards their duties;

11. errors of dispatchers;

12. non-professionalism and service inconsistency of crews caused by incorrect certification of crew members of ships in inland water transport;

13. mistakes and ignorance of sailing directions by navigators;

14. maintenance of navigation equipment in improper condition.

Even such a list of factors indicates that their quantitative accounting in a coherent and integral navigation system in order to obtain the final value of the navigational risk is extremely difficult.

Taking into account the above, one should use such a scientific apparatus that would allow solving the main problem of assessing the risks of navigation in inland waterways.

The essential features of the quantitative assessment of the levels of navigational safety include:

1. Systematization of factors determined by navigational, hydrographic and hydrometeorological conditions, the combination of which can lead to a dangerous situation.

2. Methods for obtaining quantitative information about the levels of disturbing factors.

3. The choice of criteria for dangerous situations and proof of the permissible (achieved) level of the dangerous situation.

4. Application of methods of statistical analysis of the influence of hazardous factors and generalization of the results of statistical analysis of navigation risks.

5. A posteriori statistical analysis is used both in the basic approaches to the application of methods of navigation analysis of the levels of navigation risks and in the analysis of the results of simulation modeling of navigation processes in a given area.

6. In the statistical analysis of navigation safety, classical methods of analysis are used: assessment of the main points of distributions of random variables, testing of statistical hypotheses, calculation of distribution quantiles, etc.

The methods discussed above make it possible to give an a posteriori assessment of the levels of navigation risks for ships in difficult conditions and allow obtaining, in a collected form, information about the currently achieved level of navigation risks for certain types of ships. This information can be used for comparison with the results of risk assessments obtained by simulation methods.

As shown earlier, a posteriori analysis of navigational incidents and navigational accidents for a particular type of vessel allows potential risks to be identified. Models of the influence of various factors on the formation of risks made it possible to obtain information for improving the navigation system, improving means and systems of rescue at sea, etc.

\section{Safety assessment using mathematical modeling}

The peculiarities of ship control when maneuvering in inland waterways are insufficient information about the peculiarities of navigation, really difficult navigational and hydrographic conditions (NHC) and hydrometeorological conditions (HMC), insufficient experience in pilotage, etc. 
To assess the navigational safety of ships' maneuvering in difficult conditions, simulation modeling methods are successfully applied. The basis of simulation is the use of information technology that allows reproducing a virtual navigation system.

This virtual system includes visualization of the navigation area with all stationary and temporary objects of the navigation equipment system in the navigation area, a virtual system of navigation and hydrographic conditions (depth fields, fairways, signs and buoys, alignment points, etc.), as well as the possibility of simulating HMC (wind, waves, precipitation, currents, etc.).

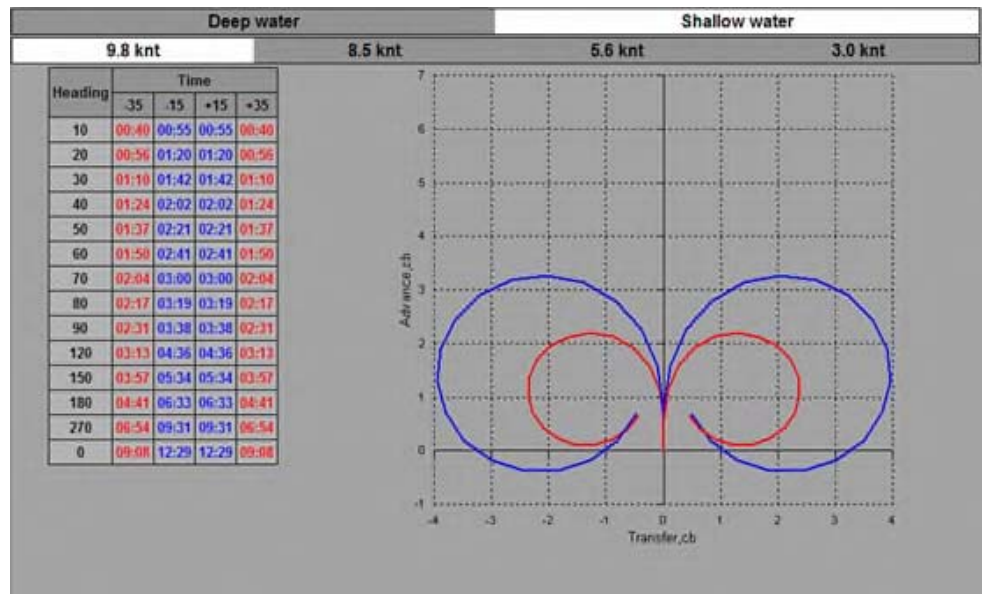

Fig. 1. An example of presentation of information about the controllability of a mathematical model of the Volga type vessel using the Transas NTPro-4000 navigation simulator.

Simulation models of navigation include ships themselves, which are described by differential equations of at least 4 orders, and also include main and auxiliary control systems with appropriate interfaces.

Experienced captains, marine pilots and trained captain-instructors can act as navigators. In general, the simulation model of navigation fully includes all the main components of a real navigation system and is effectively used for the training and certification of navigators, marine pilots, VTS operators, etc.

The essence of the simulation methods is the formation of appropriate databases on ship models, cartographic databases for DSENCI (Display System for Electronic Navigation Charts and Information) and databases on the visual surface situation in the expected navigation area for the purpose of their joint use in virtual systems for presenting information at the bridge for making decisions on controlling virtual ship in certain navigation conditions [9].

Information systems of this kind are widely used to develop practical competencies in ship management using DSENCI coupled with various external information sensors SNS, ARPA, AIS, etc.

Recently, this kind of simulation models are increasingly used to assess the navigation safety and navigation risks. The advantage of this kind of information systems is the following [10-11]:

1.Opportunities to use a mathematical model of a ship, taking into account the main features: nonlinearity of the elements of the ship's dynamics, nonlinearity of the influence of wind, waves, currents, etc. on a ship, etc. The adequacy of mathematical models can be verified by comparing its maneuverable characteristics (inertial braking characteristics) with the original. 
2. An almost complete presentation of cartographic information corresponding to current measurements, the position of dangerous isobaths, the configuration of the navigation equipment system in the navigation area, etc.

3. Formalization of the concept of characteristic winds, currents along the recommended approach routes.

4. Experienced navigators, marine pilots, simulator instructors and other experts may be involved as captains (watch assistants) of virtual vessels for solving various kinds of applied problems.

5. Simulation modeling, as a rule, precedes full-scale tests of samples of marine equipment, since it allows revealing the basic properties of the analyzed systems in more economically justifiable ways.

6. Simulation modeling does not exclude full-scale tests. However, it allows identifying in advance the strengths of the analyzed organizational and technical control system of the ship.

The weak points of the mathematical modeling method are the following [12,13]:

1. Ultimate accuracy and completeness of reproduction of NHC and HMC of the navigation area.

2.Limited opportunity for a complete description of the ship model, disturbing fac-tors and their influence on the dynamics of the ship.

3. Difficulties in the formation of the psychological and physiological environment of the bridge of a real ship, i.e. such properties of the environment, which are characterized by the responsibility for the decisions made on the maneuver, the speed of reaction, the receptivity of information, i.e. everything that distinguishes the real picture of the operator's actions on the bridge from the virtual bridge.

Thus, when using formal methods of risk assessment, it is necessary to determine the main parameters characterizing the positions of ships when maneuvering in various HMCs.

It should be admitted that at present, simulation systems are, perhaps, the only means that can be used to solve the problems of assessing the navigation safety of ships in spacelimited environment, as well as to solve the problems of assessing the minimum navigation risks for given $\mathrm{NHC}$ and ships with the maximum possible dimensions. When maneuvering, the safety of vessels will depend on the availability of sufficient distance from the side of the vessel to the appropriate lane of the fairway.

Traditionally, the position of the vessel on the fairway is usually estimated in the route coordinate system, i.e. by the distance to the turning point and the deviation along the perpendicular to the axis of the fairway. The time series of numerical values of the distances $\Delta \mathrm{x}(\mathrm{t})$ can be quite simply obtained from an electronic chart.

Simulation modeling is used to assess navigation risks in the design and construction of structures and facilities, as well as to assess risks when moving ships in space-limited environment. One of the main parameters determining the area of possible location of the vessel is the width of the vessel's maneuvering lane. It depends on the dimensions of the vessel and the drift angles. The navigational parameters characterizing the position of the vessel on the course, taking into account its dimensions, are the deviation of the center of gravity of the vessel's CG from the reference (specified) trajectory $\Delta x(t)$ and the drift angle $\mathrm{C}(\mathrm{t})[14]$.

In accordance with the rules for applying the Kolmogorov-Smirnov test [15], we will assume that the process $\Delta \mathrm{x}(\mathrm{t})$ is distributed according to the normal law and has some values of the mathematical expectation $(\mathrm{m} \Delta \mathrm{x})$ and variance $(\sigma 2 \Delta \mathrm{x})$. [15]

In addition to the process $\Delta x(t)$, the position of the vessel on the trajectory will be characterized by the width of the maneuvering lane $B(t)$ at the drift angle $C \neq 0$. [16]

The joint accounting of the statistical characteristics of the processes $\Delta x(t)$ and $B(t)$, which characterize the quality of the ship's control, makes it possible to assess the 
variability of the parameters of the ship's trajectory, and this, in turn, makes it possible to assess the navigation risks of a narrow passage.

The processes $\Delta \mathrm{x}(\mathrm{t})$ and $\mathrm{B}(\mathrm{t})$ are statistically independent. Therefore, the estimate of the total average value of the variability of the ship's trajectory will be:

$$
m_{\Sigma}=m_{\Delta x}+m_{B}
$$

where: $\mathrm{m} \Delta \mathrm{x}$ - mathematical expectation of the variability of the ship's CG; $\mathrm{mB}$ mathematical expectation of ship's lane width variability; $\mathrm{m} \Sigma$ - total mathematical expectation [16].

The variance of the variability of the lane of the vessel's trajectory will be:

$$
\sigma_{\Sigma}^{2}=\sigma_{\Delta x}^{2}+\sigma_{B}^{2}
$$

where: $\sigma 2 \Delta \mathrm{x}$ - variance of the ship's CG variability; $\sigma 2 \mathrm{~B}$ - variance of ship's lane width variability; $\sigma 2 \Sigma$ - the total variance of the variability of the parameters of the ship's motion [16].

The mathematical expectation of the width of the maneuvering lane can be determined by the formula:

$$
\frac{m_{B}}{B_{C}}=\frac{L_{C}}{B_{C}} \cdot\left(\sin m_{C}+\cos m_{C}\right),
$$

where: mc - expected drift angle; $\mathrm{mB}$ - mathematical expectation of the width of the maneuvering lane; $\mathrm{Bc}$ - width of the ship [17]. The standard deviation of the variability of the width of the maneuvering lane can be determined by the formula:

$$
\frac{\sigma_{B}}{B_{C}}=\frac{\sigma_{C}}{57,3^{\circ}} \cdot\left|\frac{L_{C}}{B_{C}} \cos C-\sin C\right|,
$$

where: $\sigma \mathrm{B}-$ standard deviation of the ship's maneuvering lane; $\sigma \mathrm{c}-$ standard deviation of the total drift of the vessel [17].

The total mathematical expectation of the variability of the ship's motion parameters will be:

$$
\frac{m_{\Sigma}}{B_{C}}=\frac{L_{C}}{B_{C}} \sin m_{C}+\cos m_{C}+m_{\Delta x} .
$$

Based on (4), the variance will be:

$$
\sigma_{B}^{2}=\left(B_{C} \cdot \frac{\sigma_{C}}{57,3^{\circ}}\left|\frac{L_{C}}{B_{C}} \cos C-\sin C\right|\right)^{2} .
$$

The results obtained make it possible to estimate the probability of occurrence of events of change in the total maneuvering lane within the permissible width of the fairway:

$$
P \cdot\left\{a_{1}<x<a_{2}\right\}=\Phi\left(\frac{a_{2}-m_{\Sigma}}{\sigma_{\Sigma}}\right)-\Phi\left(\frac{a_{1}-m_{\Sigma}}{\sigma_{\Sigma}}\right),
$$

where: $\mathrm{a} 1, \mathrm{a} 2$ - limits of the fairway dimensions; $\mathrm{x}$ - a random variable of the width of the ship's maneuvering lane; $\Phi$ - Laplace function [17]. 
The task of assessing navigation risks in such a setting will be reduced to determining the probability of ships going beyond the corresponding boundary of the fairway.

\section{Formal assessment method}

The purpose of the formal assessment method, as applied to the FAS terminology, was to assess the risk of a ship having a navigational accident while passing through a difficult navigation area. In accordance with the FAS methodology, the task was set to form a "navigator - ship - environment" system on the navigation simulator, which allows assessing navigation risks, depending on the scheme of placing drift signals in inland waterways.

The problems of choosing the corresponding section and the mathematical model of the ship from the base of the navigation simulator were solved, as well as choosing a section characterized by HMC and NHC, which allow a comprehensive assessment of the navigator's ability to keep the vessel on a line equidistant from navigational hazards, taking into account the special pilotage.

The Neva river was chosen as a water body for carrying out mathematical modeling, since the HMC and NHC are distinguished by a sharp change in the directions of the straight sections of the fairway, the alternation of narrow and wide sections, the action of dump currents, significant current velocities, and variability of currents depending on the water level and location.

Comparison of difficult for navigation sections of the Neva river has shown that they have similar navigational conditions. Taking the need to assess the importance of drift signs for orientation as a determining factor, the Ivanovskie Porogi section was chosen, where the width of the fairway changes so that a significant part of the axis of the fairway, indicated by axial alignments, passes near dangerous isobaths. Narrow sections, the main navigation equipment of which are alignments, alternate with sections where the channel width is significant, and the fairway is narrow. In such areas, drift signs equipment will play an important role for orientation.

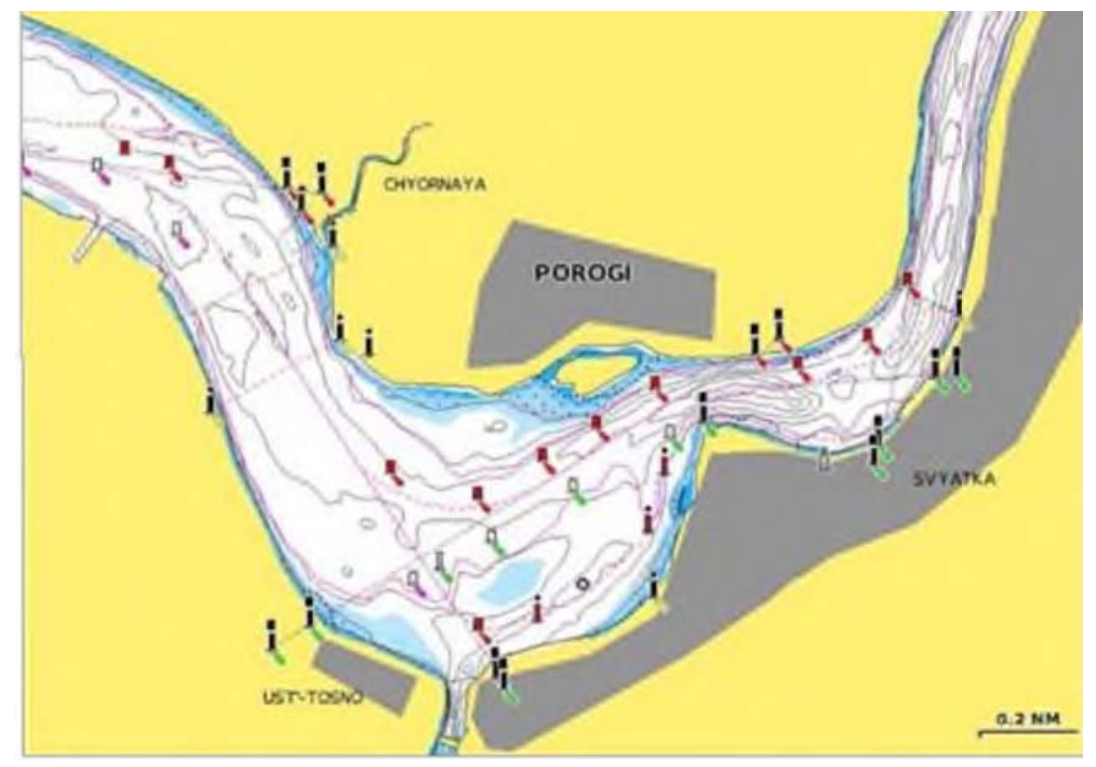

Fig. 2. Fragment of the electronic navigation map for the Ivanovskie Porogi. 
In view of the particular importance of this section for the purposes of navigation, as well as the complexity and variability of navigation conditions, when carrying out trial run on a navigation simulator, the navigators navigated the vessel in accordance with the recommendations for navigation and being very careful.

Mathematical modeling of the controlled movement of a design vessel of the Vol-ga type in difficult hydrometeorological conditions was carried out on the section of the Neva river, Ivanovskie Porogi, using the NTPro 4000 navigation simulator and DSENCI. As a result, the values of the vessel's center of gravity (CG) deviation and the drift angle were obtained for cases of movement with cargo up and down in the absence of buoys in their regular places, and when their minimum number required for orientation was set. When the vessel moves along the section under consideration, the vessel's draft is in a certain range, the local navigation rules allow movement be-yond the edges of the fairway. However, this increases the load on the navigator, since the ability to navigate by drift signs completely disappears or decreases to a minimum, because the edge of the fairway is located on one side, and the determination of the direction of movement is carried out by comparing the change in the position of the navigation signs from both sides.

Thus, it will be of interest for science and practice to assess both the ability of the navigator controlling the ship using radar to keep the ship equidistant from dangerous isobaths and the ability to navigate by drift signs and keep the ship on the recommended paths, the direction of which is set by the axial alignments.

The results characterizing the movement of the vessel were analyzed by classical methods of statistical analysis $[18,19]$. Histograms and statistical moments of the time series of the deviation of the ship's CG $\Delta x(t)$ and the drift angle $C(t)$ obtained using modern applications for processing statistical data [20] are shown in Fig. 3, 4 and in table 2.
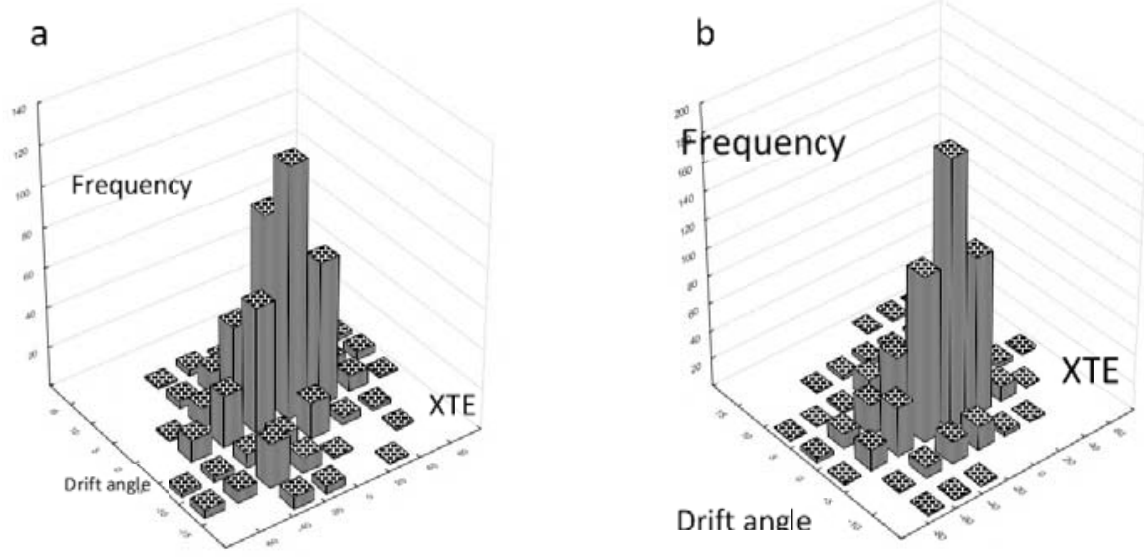

Fig. 3. Histograms of the distributions of the processes of deviations of the ship's center. of mass and the total drift angles when navigating the vessel along the Ivanovskie Porogi section in the absence of drift signs: a) when following down; b) when following up.

The presentation of data sets on the deviations of the ship's center of mass together with the drift angles in the form of three-dimensional histograms allows not only simplifying and effectively representing the sequence of observations and, thus, increasing the clarity of the available information, but also performing three-dimensional visual analysis. This approach provides very detailed data and is the most efficient way to present and transmit information, as well as emphasize key information, high-light links between specific indicators, or reflect trends. Presenting data as graphs or charts can be a useful analytical tool and, if the data is effectively interpreted, it can facilitate decision making. 
Comparison of the histograms of the distributions of the processes of deviations of the ship's center of mass and the total drift angles when navigating the vessel along the Ivanovskie Porogi section in the absence of drift signs when following down and up made it possible to determine a parameter that optimally takes into account the influence of all external factors on the vessel and using which it is possible to assess the navigational safety of the ship when passing curved sections. This parameter is the drift angle, since it takes into account both the total drift angle from the wind and current and drift by correcting the movement of the vessel along a curved trajectory, which is necessary to compensate for the errors of the ship's navigation.

a

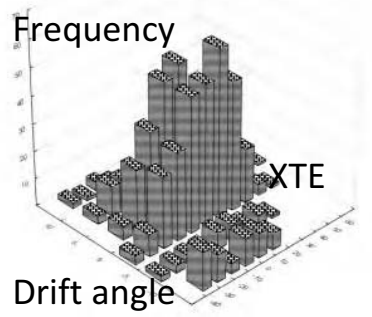

b

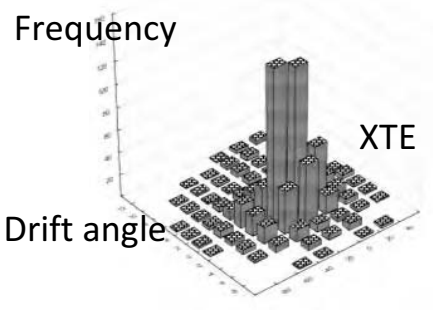

Fig. 1. Histograms of the distributions of the processes of deviations of the ship's center of mass and the total drift angles when navigating the ship along the Ivanovskie Porogi section in the presence of drift signs at regular places: a) when following down; b) when following up.

When passing sharp turns of the section under consideration, when the navigator needs to control the movement to keep the vessel in a lane of considerable width, or in the process of holding the vessel when entering a narrow rectilinear section, the corresponding distances between the bow and stern ends and the edges of the fairway can differ significantly, which is explained by the practice of performing maneuvers.

When the vessel approaches the edges of the fairway at a distance less than planned due to a short-term loss of controllability of the vessel, which is understood as a sharp increase in external forces, which cannot be compensated for in a timely manner by steering. Thus, in the process of maneuvering, it is not possible to timely prevent the turn of the vessel caused by external forces, and the vessel acquires a significant lateral deviation caused both by the speed acquired not from the action of external forces but from the own speed of the vessel. The forces of hydrodynamic interaction between the ship and the edges of the fairway will act so that the distance is reduced even more. If we take into account that during simulation modeling the orientation was carried out visually, then keeping the reserve upwards is justified and corresponds to the practice of steering the ship when passing curvilinear sections. 
Table 2. Generalized comparative data on the characteristics of the processes $\Delta x(t)$ and $C(t)$ of the design vessel when passing the Ivanovskie Porogi section.

\begin{tabular}{|c|c|c|c|c|c|c|}
\hline \multirow[t]{2}{*}{ Parameter name } & \multicolumn{2}{|l|}{ Upward } & \multirow[b]{2}{*}{$\begin{array}{l}\text { Differe } \\
\text { nce }\end{array}$} & \multicolumn{2}{|c|}{ Downward } & \multirow[b]{2}{*}{$\begin{array}{l}\text { Differe } \\
\text { nce }\end{array}$} \\
\hline & $\begin{array}{l}\text { With } \\
\text { buoys }\end{array}$ & $\begin{array}{l}\text { Witho } \\
\text { ut } \\
\text { buoys }\end{array}$ & & $\begin{array}{l}\text { With } \\
\text { buoys }\end{array}$ & $\begin{array}{l}\text { Without } \\
\text { buoys }\end{array}$ & \\
\hline $\begin{array}{l}\text { Average value of the } \\
\text { deviation of the } \\
\text { vessel's center of } \\
\text { mass CM (m) }\end{array}$ & $\begin{array}{l}-15.80 \\
\text { (to the } \\
\text { left } \\
\text { side) }\end{array}$ & $\begin{array}{l}-12.06 \\
\text { (to the } \\
\text { left } \\
\text { side) }\end{array}$ & $\begin{array}{l}-3.74 \\
(- \\
23.69 \% \\
)\end{array}$ & $\begin{array}{l}0.64 \text { (to } \\
\text { the right } \\
\text { side) }\end{array}$ & $\begin{array}{l}5.35 \\
\text { (to the } \\
\text { right } \\
\text { side) }\end{array}$ & $\begin{array}{l}+4.72 \\
(+737.3 \\
2 \%)\end{array}$ \\
\hline $\begin{array}{l}\text { Average value of drift } \\
\text { angle change }\left(^{\circ}\right)\end{array}$ & 0.1925 & 0.1931 & $\begin{array}{l}-0.0006 \\
\left({ }^{\circ}\right) \\
(0.0 \%) \\
\end{array}$ & -0.582 & -0.813 & $\begin{array}{l}+0.23 \\
(+39.74 \\
\%) \\
\end{array}$ \\
\hline $\begin{array}{l}\text { Maximum deviation } \\
\text { of the vessel's center } \\
\text { of mass CM (m) to the } \\
\text { left side }\end{array}$ & 87.0 & 84.0 & $\begin{array}{l}-3 \mathrm{~m} \\
(- \\
3.45 \%)\end{array}$ & 43.0 & 78.0 & $\begin{array}{l}+35 \\
(+81.39 \\
\%)\end{array}$ \\
\hline $\begin{array}{l}\text { Maximum deviation } \\
\text { of the vessel's center } \\
\text { of mass CM (m) to the } \\
\text { right side }\end{array}$ & 57.0 & 87.0 & $\begin{array}{l}+30 \mathrm{~m} \\
(52.63 \\
\%)\end{array}$ & 71.0 & 82.0 & $\begin{array}{l}+11 \mathrm{~m} \\
(+15.49 \\
\%)\end{array}$ \\
\hline $\begin{array}{l}\text { Maximum drift angle } \\
\text { to the left side }\end{array}$ & 8.0 & 11.0 & $\begin{array}{l}+3\left(^{\circ}\right) \\
(+37.5 \\
\%)\end{array}$ & -15.0 & -21.0 & $\begin{array}{l}+6\left(^{\circ}\right) \\
(+40 \%)\end{array}$ \\
\hline $\begin{array}{l}\text { Maximum drift angle } \\
\text { to the right side }\end{array}$ & 14.0 & 19.0 & $\begin{array}{l}+5\left(^{\circ}\right) \\
(+35.71 \\
\%)\end{array}$ & 12.0 & 13.0 & $\begin{array}{l}+1\left(^{\circ}\right) \\
8.33 \%\end{array}$ \\
\hline Dispersion $(\mathrm{m})$ & 571.12 & 478.65 & & 377.15 & 563.27 & \\
\hline Dispersion deg. $\left({ }^{\circ}\right)$ & 11.29 & 13.68 & & 21.89 & 26.47 & \\
\hline $\begin{array}{l}\text { Standard deviation } \\
\text { (m) }\end{array}$ & 23.898 & 21.878 & $\begin{array}{l}-2.11(- \\
8.45 \%)\end{array}$ & 19.420 & 23.733 & $\begin{array}{l}+4.31 \\
(+22.21 \\
\%) \\
\end{array}$ \\
\hline $\begin{array}{l}\text { Standard deviation } \\
\text { deg. }\left({ }^{\circ}\right)\end{array}$ & 3.3606 & 3.699 & $\begin{array}{l}+0.34 \\
(+10.12 \\
\%)\end{array}$ & 4.678 & 5.145 & $\begin{array}{l}+0.47 \\
\left({ }^{\circ}\right) \\
9.97 \%\end{array}$ \\
\hline $\begin{array}{l}\text { Laplace function } \\
\text { argument }\end{array}$ & 3.2872 & 3.2002 & & 3.3813 & 4.2576 & \\
\hline $\begin{array}{l}\text { Likelihood of going } \\
\text { over the edge of the } \\
\text { fairway }\end{array}$ & $\underline{1.0 \cdot 10^{-2}}$ & $\frac{4.0 \cdot 10^{-}}{\underline{2}}$ & & $\underline{5.0 \cdot 10^{-3}}$ & $\underline{8.0 \cdot 10^{-3}}$ & \\
\hline
\end{tabular}

A formal assessment of the safety of navigation, based on the consistent application of the method of mathematical modeling to determine the parameters of the vessel's movement when following a section that is difficult for navigation - Ivanovskie Porogi, and subsequent analysis using the methods of mathematical statistics made it possible to obtain the following results:

- $\quad$ assess the navigational risks of navigating a vessel under various schemes of placing drift signs together with the influence of various hydrometeorological factors - wind, current and shallow water;

- $\quad$ substantiate practical recommendations for navigating a vessel under various sailing conditions;

- determine the optimal criterion for assessing the possibility of a safe passage of a vessel through areas that are difficult for navigation: this criterion is the magnitude of the navigation risk; 
- a method of presenting information has been determined, which, in ship conditions, makes it possible to easily and quickly assess the ability of the vessel to safely navigate a specific section of the waterway;

- $\quad$ identify a criterion for assessing the ability of a vessel to safely navigate a section of the waterway, where the dimensions of the vessel play a primary role; this criterion is the width of the maneuvering lane.

It should be emphasized that the numerical values of the levels of navigation risks make it possible to determine not only the scheme of placing the navigation signs, but also hydrometeorological factors that limit the safe passage of the vessel under optimal control. It is a known fact that the success of a ship's maneuvering in difficult hydrometeorological conditions largely depends on the professional training of the navigator, his sailing experience in the area, preparation for work in extreme situations, the technical condition of the ship and the state of the ship's controls, steering gear, main and auxiliary engines of the ship, equipping of fairways in rivers with navigation equipment. Decisions on the continuation of the movement of the vessel or on its termination should be made on a caseby-case basis, depending on the specific conditions and circumstances.

\section{Conclusion}

The application of the formal safety assessment method based on the splicing of the mathematical and probabilistic modeling method for assessing navigation safety and the subsequent calculation of navigation risks when navigating large-tonnage vessels in spacelimited environment showed the following:

1. Simulation modeling made it possible to identify the level of expected navigation risks when maneuvering for passage near the edges of the fairway, separate navigation hazards, etc. at level of 10-2.

2.Levels of navigation risks when navigating ships along straight sections of fairway, as well as when passing turns with curvature radii that meet the requirements of guidance documents at level of 10-3.

3. Levels of navigation risks substantially depend on the ability of the navigators to consistently assess the position of the vessel relative to the axis of the fairway and correct this movement.

\section{References}

1. D. J. House, "Watchkeeping duties," Seamanship Techniques, 297-321 (2004)

2. M. S. Solmaz, B. Özsever, A. Gúllú, Ç. Meźe, TransNav, the International Journal on Marine Navigation and Safety of Sea Transportation 14(3), 565-571 (2020)

3. P. Brodie, "International Convention on Standards of Training, Certification and Watch-keeping for Seafarers (STCW)," Commercial Shipping Handbook, 230-231 (2014)

4. A. Mentes, H. Akyildiz, M. Yetkin, N. Turkoglu, Safety Science 79, 1-10 (2015)

5. J-H. Kim, Journal of the Korean Society of Marine Engineering 33(2), 362-367 (2009)

6. M. B. Zaman, A. Santoso, E. Kobayashi, N. Wakabayashi, A. Maimun, TransNav, the International Journal on Marine Navigation and Safety of Sea Transportation 9(1), 6772 (2015)

7. A. Papanikolaou, K. Bitha, E. Eliopoulou, N. P. Ventikos, Maritime Technology and Engineering, 245-252 (2014) 
8. A formal assessment of safety (FAS) manual for use in decision-making in IMO. MSC/Circ.1023-MEPC/Circ.392 as amended (in Russian and English), SaintPetersburg, ZAO TsNIIMF, 138 (2011)

9. V. T. Pham, H. Kobayashi, The Journal of Japan Institute of Navigation 118, 283-289 (2008)

10. V. V. Karetnikov, A. A. Prokhorenkov, K. I. Efimov, A. A. Butsanets, IOP Conf. Ser.: Mater. Sci. Eng. 918, 012091 (2020)

11. V. Frette, G. Kleppe, K. Christensen, AIP Conference Proceedings 1332, 276 (2011)

12. Y. A. Ahmed, M. A. Hannan, I. M. Kamal, Ocean, Offshore and Arctic Engineering Division 7A: Ocean Engineering (2018)

13. G. J. Macfarlane, N. Bose, J. T. Duffy, Journal of Ship Production and Design 30(3), 109-125 (2014)

14. V. Karetnikov, I. Pashchenko, V. Kozlov, IOP Conf.Ser.: Mater. Sci. Eng. 811(1), 012005 (2020)

15. G. G. Abezgauz, A. P. Tron, Yu. N. Kopenkin, I. A. Korovina, Handbook of Probability Calculations, 560 (Voenizdat, Moscow, 1970)

16. S. N. Nekrasov, K. I. Efimov, D. V. Trenenkov, Bulletin of Admiral Makarov State University of Maritime and Inland Shipping 1, 194 (2014)

17. S. N. Nekrasov, Yu. G. Andreev, Journal of the University of Water Communications, Saint-Petersburg, SPBSUWC, 247 (2012)

18. E. S. Wentzel, I. A. Ovcharov, Probability theory and its engineering applications, 342 ("KNORUS", Moscow, 2010)

19. N. M. Gruzdev, Mathematical processing and analysis of navigation information, 222 (Voenizdat, Moscow, 1979)

20. B. Yu. Lemeshko, Statistical data analysis, modeling and research of probabilistic patterns. Computer approach, 888 (SRC INFRA-MII, Moscow, 2015) http://znanium.com/bookread.php?book=515227, last accessed 2021/01/21. 